\title{
Carrier-Based Pwm Technique for Inverter-Fed Multiphase Induction Motor
}

\author{
B. Jyothi ${ }^{1}$, M. Venugopala Rao ${ }^{2}$ \\ ${ }^{1}$ Departement of Electrical Engineering, KL University, India \\ ${ }^{2}$ Departement of Electrical Engineering, PVPSIT, JNT University, India
}

\section{Article Info \\ Article history: \\ Received Feb 20, 2016 \\ Revised Apr 5, 2016 \\ Accepted Apr 25, 2016}

\section{Keyword:}

Carrier-Based pulse width modulation (PWM)

Universal voltage source inverters (VSIs)

Star and delta connection Third harmonic injection

\section{Corresponding Author:}

B. Jyothi

Departement of Electrical Engineering,

KL University, India

Email: jyothieee@kluniversity.in

\begin{abstract}
Multiphase (more than three phases) is very much popular due to their eminent features compared to conventional three-phase counter parts. In order to drive the multiphase machine, it requires same phase input w.r.t the no of phases at the output. This paper mainly focuses on five phase, because even after failure of one phase, the performance does not degraded much. Voltage source inverters (VSIs) are used to feed the induction motor. Voltage source inverters (VSIs) switches are ON and OFF precisely to control the output. In order to implement harmonic waveform characteristic, carrier based PWM (pulse width modulation) is performed. By using with and without third harmonic injection machine torque is highly improved. Using MATLAB software, the simulation results are presented in the form of computer traces and high traded performance of the machine are discussed.
\end{abstract}

Copyright (c) 2016 Institute of Advanced Engineering and Science. All rights reserved.

\section{INTRODUCTION}

It is considered as the workhorse for the industry. Induction machines has almost replaced the D.C machine in the industry due to the simplicity of the design, low-cost, low maintenance cost, ruggedness and direct connection to A.C power source compared to D.C. maximum total power consumption in the industrial sector is from "induction motors" only. Induction motor fed with voltage source inverter, the magnitude of stator current is determined by means of leakage inductance of the motor and source amplitude at harmonic frequencies. Hence it needs to diminish the magnitude along with rise of frequency of torque oscillations [1] also reduces the rotor harmonic current losses, dc link current harmonics by increasing the number of phases of the machine drive. Raising the number of phases then it is feasible to amplify the torque per rms ampere for the same machine output. Five-phase Induction motor acquire dominance features over three phase motor drives such as using existing low voltage power devices to realize high power drives. Applications for multiphase induction machine are mainly concerned on aircrafts, electric ship propulsion, and hybrid electric vehicles (HEV) etc.

\section{BLOCK DIAGRAM FOR MULTI PHASE INDUCTION MOTOR}

Multiphase induction motor feed by a voltage source inverter. As shown in Figure 1, VSI dc link voltage is varied from the controlled rectifier. The output of the inverter is fed to five phase induction motor. Rectifier converts ac to dc. Here the pulsating dc is obtained from the rectifier, it contains harmonics. These harmonics are eliminated by using filters. Hence the input of the five phase inverter is pure dc. 


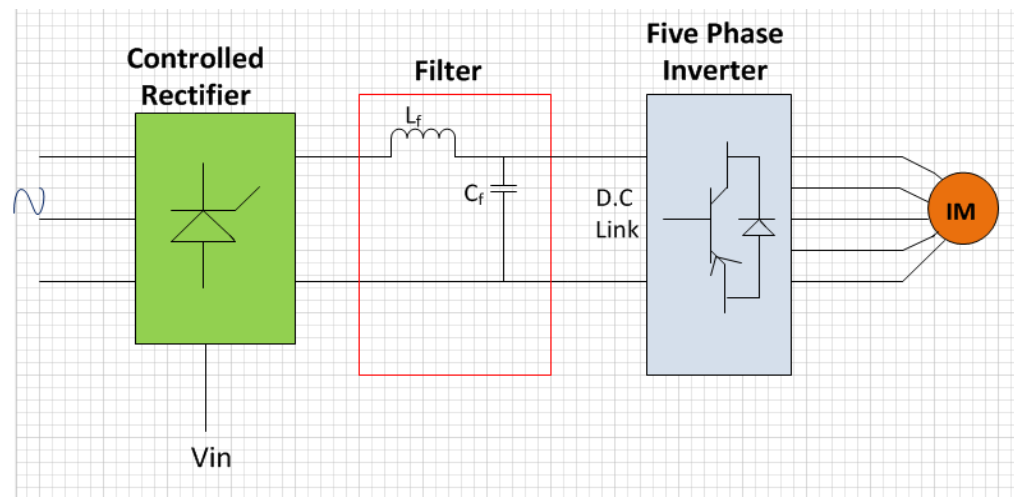

Figure 1. Five phase VSI fed Induction Motor

Multi phase motor drive diminishes current ripple, unfailing under inadequate condition, and reduction in phase current.

\section{TWO LEVEL FIVE LEG VOLTAGE SOURCE INVERTER}

Here, the upper switch and lower switch are termed as leg because to understand the inverted action very easily such as to be termed as upper switch or upper leg and lower switch or lower leg (Figure 2). The phase delay between each leg is $72^{0}$ where as phase delay between the consecutive switches is 360 . The below schematic diagram consists of fully controllable five phase voltage source inverter. VSI is operated in ten modes ,in each mode five switches are in ON state, two switches from the upper group and three switches from lower group or vice versa. In order to avoid the short circuiting in any leg of the inverter no two switches are turned on (Figure 3).

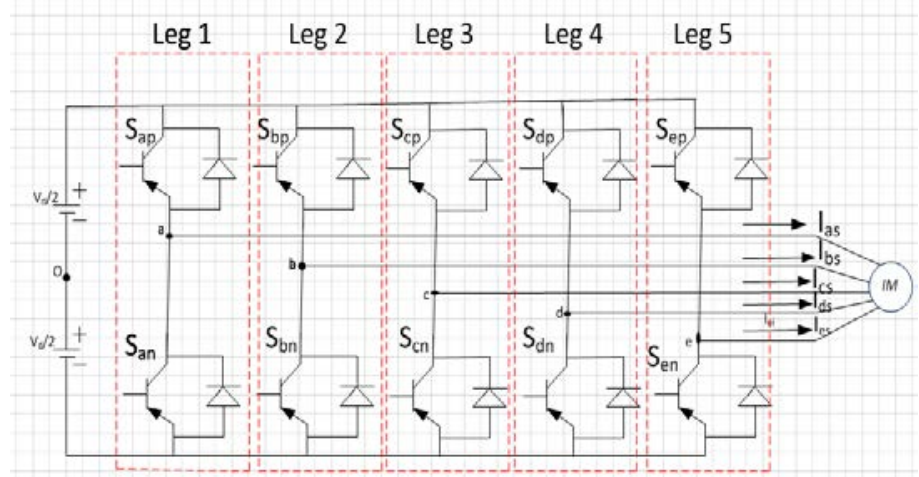

Figure 2. Two Level Five Leg voltage source inverter

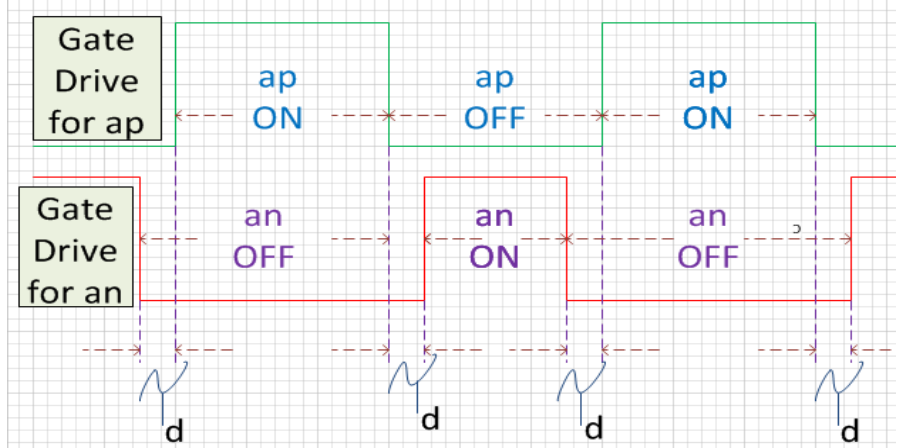

Figure 3. Representation of dead line and how power switch is working in-terms of plotted waveform 


\section{MATHEMATICAL REPRESENTATION AND ANALYSIS OF MULTI PHASE INDUCTION}

\section{MOTOR}

The operation of five leg inverter switches is in two states. Each leg consists of two switches. When one switch is ON state and the other switch is in OFF state. In Figure 2, the Upper leg switches are represented as $\mathrm{S}_{\mathrm{ap}}, \mathrm{S}_{\mathrm{bp}}, \mathrm{S}_{\mathrm{cp}}, \mathrm{S}_{\mathrm{dp}}, \mathrm{S}_{\mathrm{ep}}$, where as lower leg switches are $\mathrm{S}_{\mathrm{an}}, \mathrm{S}_{\mathrm{bn}}, \mathrm{S}_{\mathrm{cn}}, \mathrm{S}_{\mathrm{dn}}$, $\mathrm{S}_{\mathrm{en}}$. where First subscript refers to corresponding phase and second subscript refers to upper leg or lower leg switch (p-upper leg, n-lower leg). When switch in ON, it takes the value of unity and in OFF state it takes the value of zero. The generalised switching device can be represented as $S_{i j}$. Where "i” represents the corresponding phase which it is to be associated and " $\mathrm{j}$ " represents the upper and lower device of the particular leg of the inverter. Five leg inverter output voltage equations are expressed in terms of input dc voltage $V_{d}$ are as follows.

$$
\begin{aligned}
v_{i o}=\frac{v_{d}}{2}(2 \operatorname{Sip}-1)= & v_{\text {in }}+v_{n o} i=a, b, c, d, e \\
v_{a o}=\frac{v_{d}}{2}(\text { sap- san }) & =\frac{v_{d}}{2}(\operatorname{sap}-(1-\operatorname{sap})) \\
& =\frac{v_{d}}{2}(\operatorname{sap}-1+\operatorname{sap}) \\
& =\frac{v_{d}}{2}\left(2 S_{a p}-1\right) \\
& =v_{a n}+v_{n o}
\end{aligned}
$$

similarly,

$$
\begin{aligned}
& v_{b o}=\frac{v_{d}}{2}\left(2 S_{b p}-1\right)=v_{b n}+v_{n o} \\
& v_{c o}=\frac{v_{d}}{2}\left(2 S_{c p}-1\right)=v_{c n}+v_{n o} \\
& v_{d o}=\frac{v_{d}}{2}\left(2 S_{d p}-1\right)=v_{d n}+v_{n o} \\
& v_{e o}=\frac{v_{d}}{2}\left(2 S_{e p}-1\right)=v_{e n}+v_{n o}
\end{aligned}
$$

Now, equating L.H.S and R.H.S terms, Hence, we get

$$
v_{a o}+v_{b o}+v_{c o}+v_{d o}+v_{e o}=v_{a n}+v_{b n}+v_{c n}+v_{d n}+v_{e n}+v_{n o}+v_{n o}+v_{n o}+v_{n o}+v_{n o}
$$

Therefore,

where,

$$
v_{a o}+v_{b o}+v_{c o}+v_{d o}+v_{e o}=v_{a n}+v_{b n}+v_{c n}+v_{d n}+v_{e n}+5 v_{n o}
$$

$$
\begin{aligned}
& v_{a o}+v_{b o}+v_{c o}+v_{d o}+v_{e o}=\frac{v_{d}}{2}\left(2 S_{a p}-1\right)+\frac{v_{d}}{2} \\
& \left(2 S_{b p}-1\right)+\frac{v_{d}}{2}\left(2 S_{c p}-1\right)+\frac{v_{d}}{2}\left(2 S_{d p}-1\right)+\frac{v_{d}}{2}\left(2 S_{e p}-1\right)
\end{aligned}
$$

Now, balanced five -phase system, and eliminate the higher order terms (or) represented as simply zero. Then

$$
v_{a n}+v_{b n}+v_{c n}+v_{d n}+v_{e n=0}
$$

Substitute equation 9 in equation 8 , then

$$
v_{a o}+v_{b o}+v_{c o}+v_{d o}+v_{e o}=5 v_{n o}
$$

Substitute eq.8, in eq.10 then, 
$5 v_{n o}=\frac{v_{d}}{2}\left(2 S_{a p}-1\right)+\frac{v_{d}}{2}\left(2 S_{b p}-1\right)+\frac{v_{d}}{2}\left(2 S_{c p}-1\right)+\frac{v_{d}}{2}\left(2 S_{d p}-1\right)+\frac{v_{d}}{2}\left(2 S_{e p}-1\right)$

$v_{a n}, v_{b n}, v_{c n}, v_{d n}, v_{e n}$ Indicates the phase voltages w.r.to the load and $v_{n o}$ refers voltage w.r.t the load.

\section{PULSE WIDTH MODULATION (PWM) USING INVERTER FED MULTI PHASE INDUCTION MOTOR}

According to the switches ON and OFF of the inverter, pulses are generated. Consider the magnitude of the pulses either unity or Zero depends upon the switching action. From the fourier analysis the expressions are written as follows.

$$
\begin{aligned}
\mathrm{S}_{\mathrm{ip}} & =0.5\left(1+M_{i p}\right) \\
2 \mathrm{~S}_{\mathrm{ip}} & =\left(1+M_{i p}\right) \\
2 \mathrm{~S}_{\mathrm{ip}} & -1=M_{i p} \\
M_{i p} & =\frac{2\left(v_{i n}+v_{n 0}\right)}{v_{d}}, i=a, b, c, d, e
\end{aligned}
$$

\section{ZERO- SEQUENCE SIGNAL UNBIASED VOLTAGE}

From equation 2 to 6 , neutral voltage $v_{n 0}$, can be written as

$$
\begin{aligned}
& \frac{v_{d}}{2}\left(2 S_{i p}-1\right)=v_{i o} \\
& v_{n o}=\frac{v_{d}}{2}\left(2 S_{i p}-1\right)-v_{i n} \\
& \frac{2 v_{n o}}{v_{d}}=2 S_{i p}-1-\frac{2 v_{i n}}{v_{d}} \\
& 2 S_{i p}-1=\frac{2 v_{i n}}{v_{d}}+\frac{2 v_{n o}}{v_{d}} \\
& 2 S_{i p}-1=m_{i p p}+m_{o}
\end{aligned}
$$

Where, $m_{i p p}=\frac{2 v_{i n}}{v_{d}}, m_{o}=\frac{2 v_{n o}}{v_{d}}$ and $i=a, b, c, d, e$. The upper switch is turned ON in VSI

$$
m_{o}=1-m_{i p p}
$$

When the upper switch is turned off in VSI, then

$$
m_{o}=-1-m_{i p p}
$$

There are six feasible solutions for Mo from eq. (19) and eq. (20) since the equation is determined and yielding a infinite number of possibilities. However, Mo lies between 1 and -1 since the normalized high-frequency triangular signal also lies within this range [1]. The appropriate solution has to be obtained from equation (19) and (20). With the following definitions,

$$
M_{\text {max }}=\operatorname{Max}\left(m_{i p p}\right) \quad M_{\text {min }}=\operatorname{Min}\left(m_{i p p}\right)
$$

Here $m_{i p p}$ consists of two values i.e Max and Min

The extrema of the $m_{0}$ are $\left(1-M_{\max }\right),\left(-1-M_{\min }\right),\left(1-M_{\min }\right)$ and $\left(-1-M_{\max }\right)$ of which have the magnitudes between the range $(1,-1)$. The two solutions are now linearly dependent to determine the average value of $m_{0}$, where $0 \leq \alpha \leq 1$ and is given by [2]

$$
\begin{aligned}
& \left\langle m_{0}\right\rangle=\alpha\left(-1-M_{\min }\right)+(1-\alpha)\left(1-M_{\max }\right) \\
& \left\langle m_{0}\right\rangle=(1-2 \alpha)+(\alpha-1)\left(M_{\max }\right)-\alpha M_{\min }
\end{aligned}
$$


Here the No. of carrier pulse width modulation signals are provided by the value of $\alpha$.

By changing $\delta$, different discontinues modulation signals are obtained. Figure 4 through Figure 7 has defined the modulation signals and corresponding phase ' $a$ ' load voltage at different values of $\alpha$ and modulation signals $\delta$ [2]. In this result the peak fundamental voltage is $150 \mathrm{~V}$, and third harmonic voltage is $15 \mathrm{~V}$. The D.C voltage is $300 \mathrm{~V}$. Figure 4 through Figure 9 the result only having the fundamental component is considered, whereas Figure 10 through Figure 24 shows the result having the fundamental voltage and third harmonic voltage has been considered. When $\alpha=0.5$ carrier based modulation scheme for known space vector modulation scheme where null states are equally weighed.

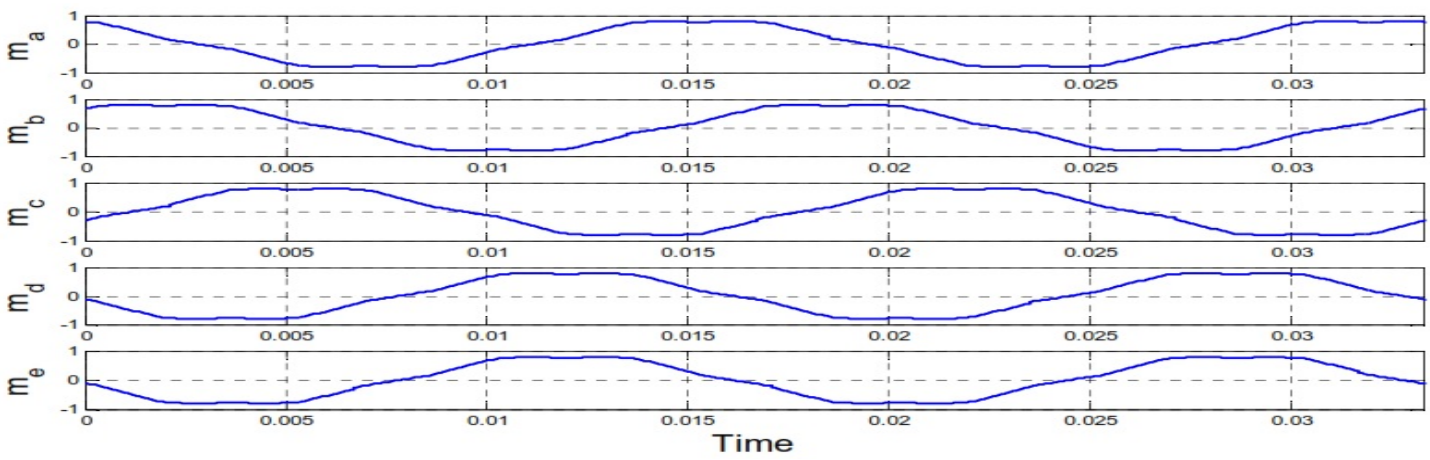

Figure 4. Five phase modulation signals for $\alpha=0.5$

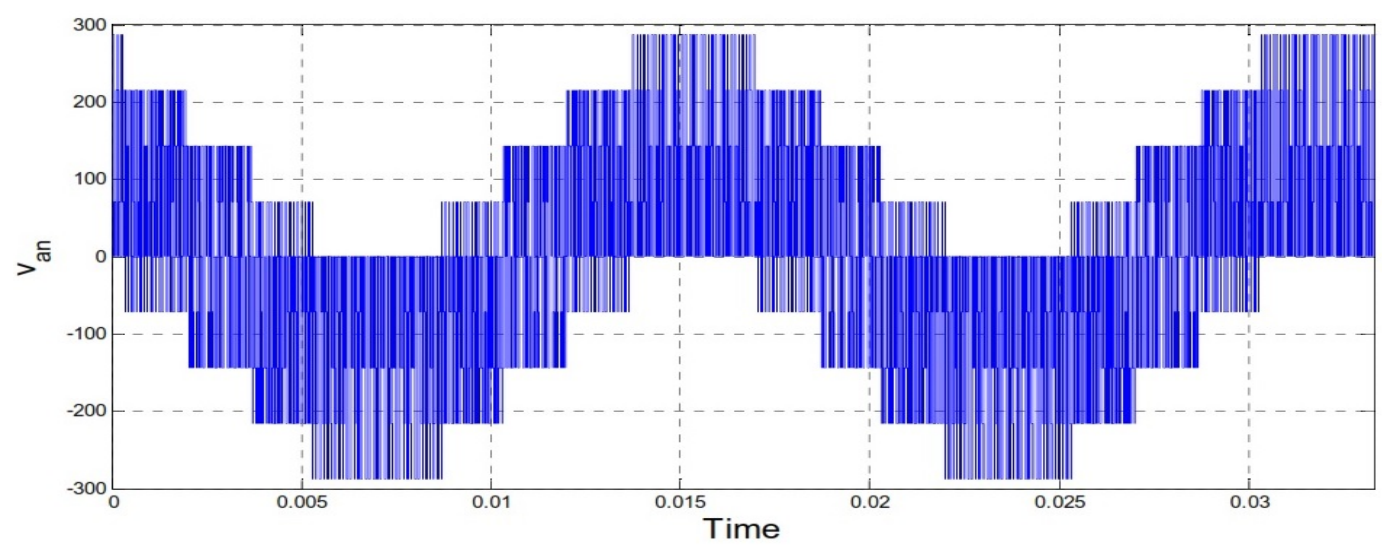

Figure 5. Phase 'a' load voltage, $\alpha=0.5$

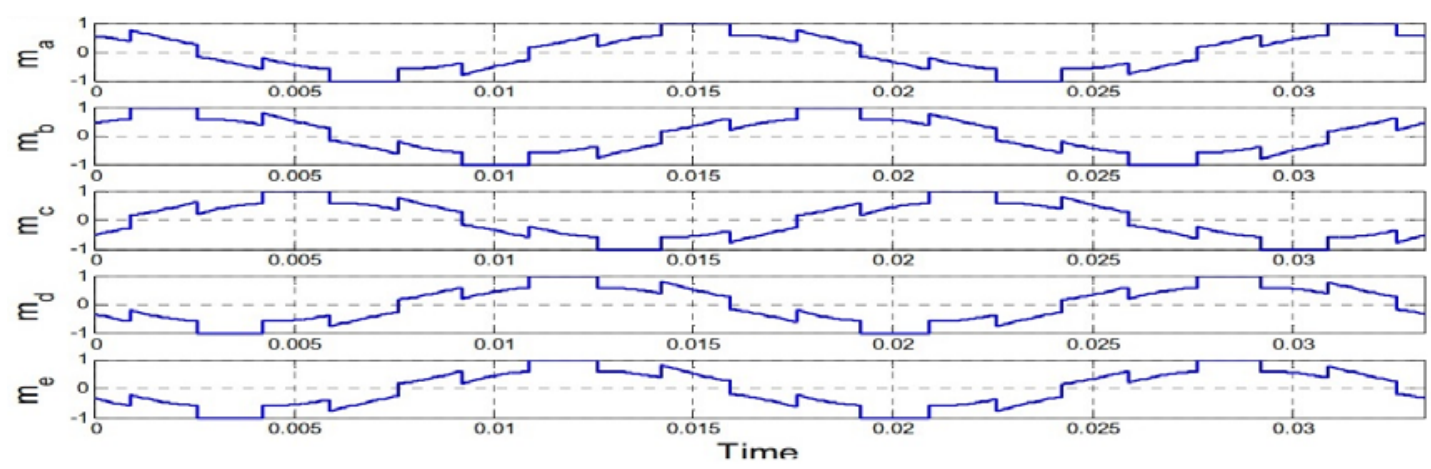

Figure 6. Five phase modulation signals for, $\delta=-36^{0}$ 


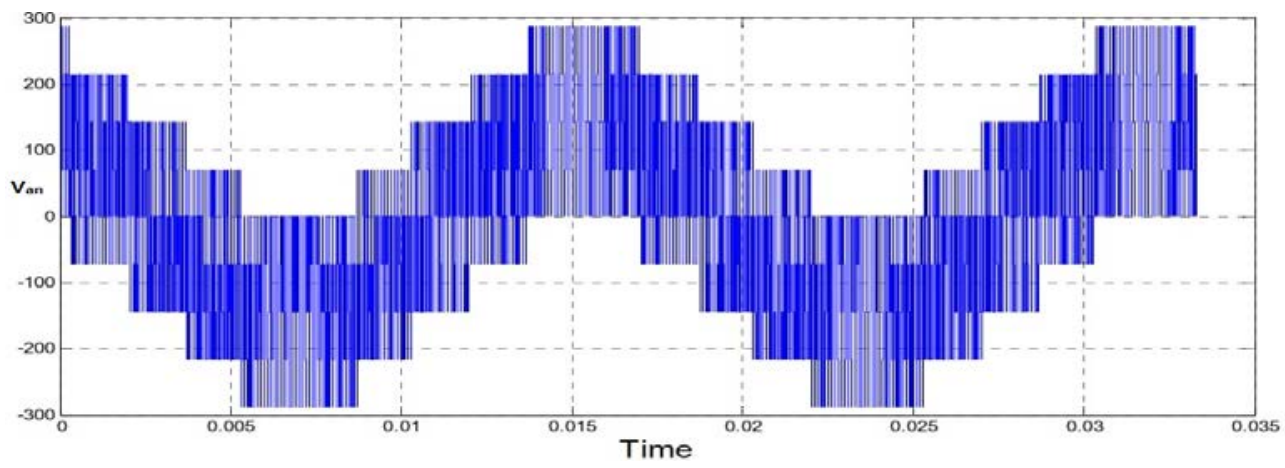

Figure 7. Phase ' $a$ ' load voltage,$\delta=-36^{0}$

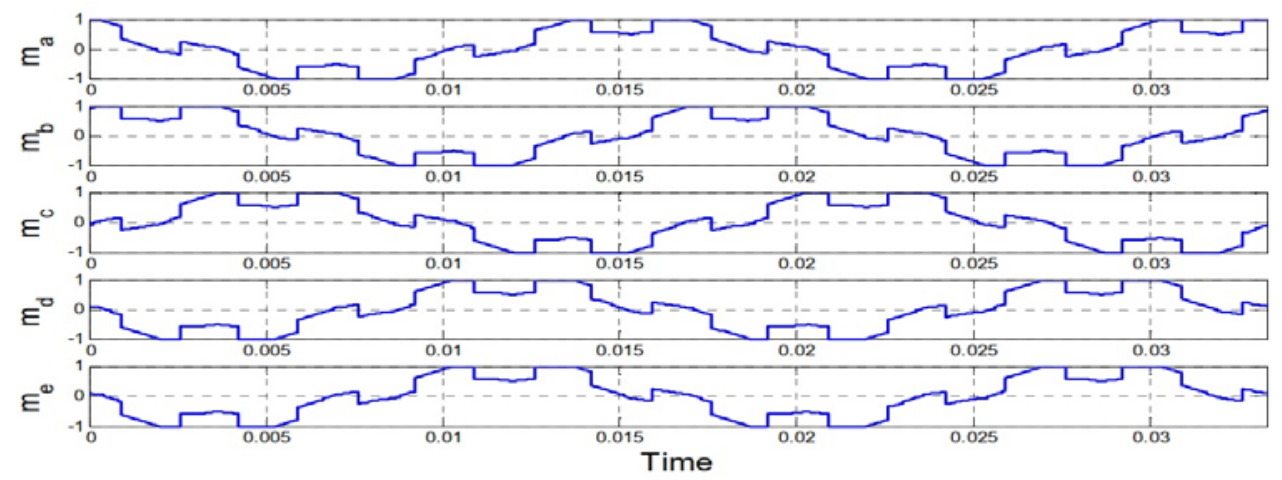

Figure 8 . Five phase modulation signals for, $\delta=0^{0}$

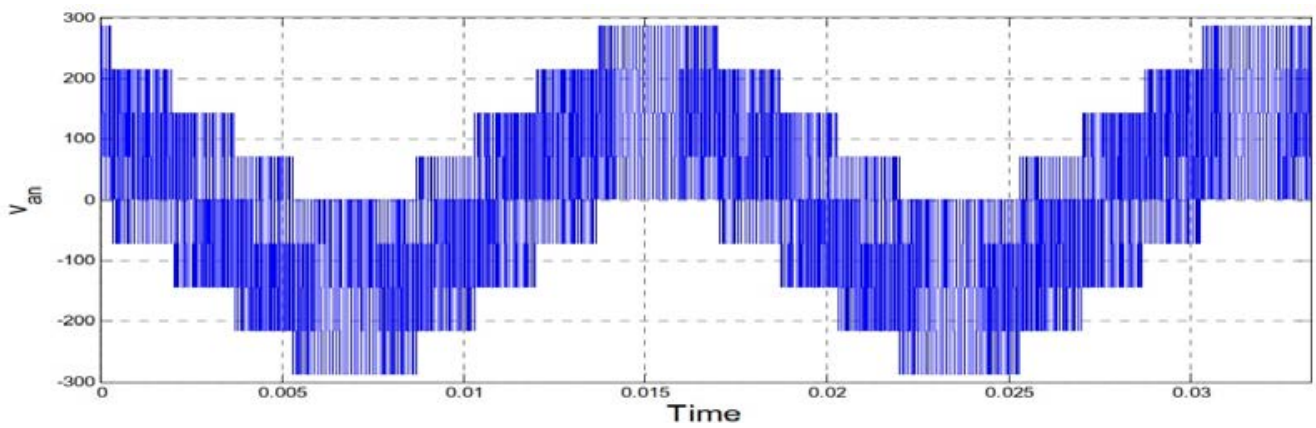

Figure 9. Phase 'a' load voltage, $\delta=0^{0}$

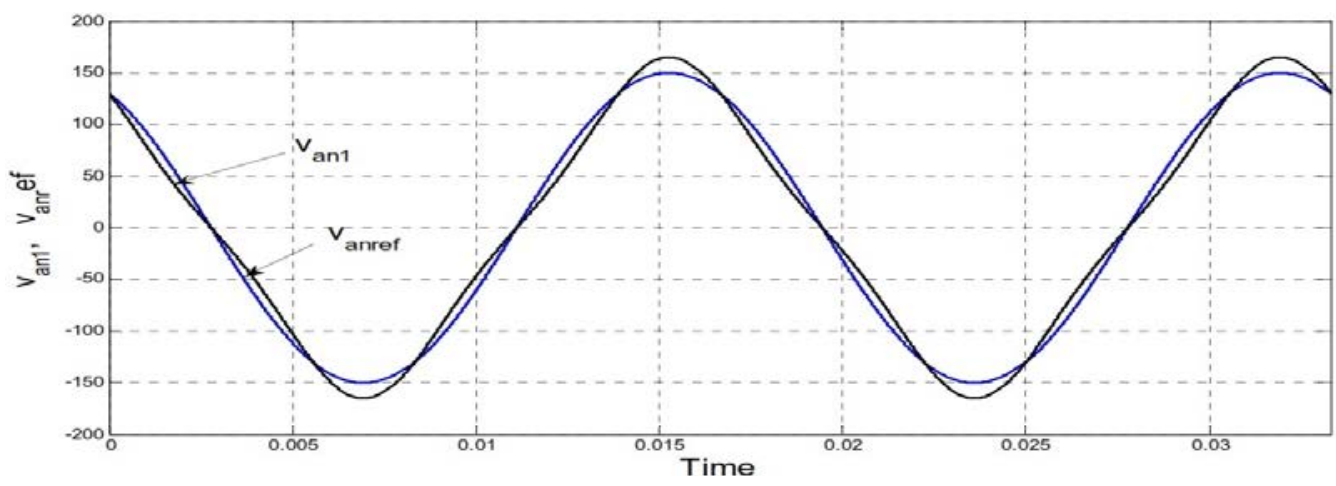


Figure 10. Phase 'a' fundamental and reference voltage, $\delta=36^{0}, V_{m 3}=+15 \mathrm{v}$

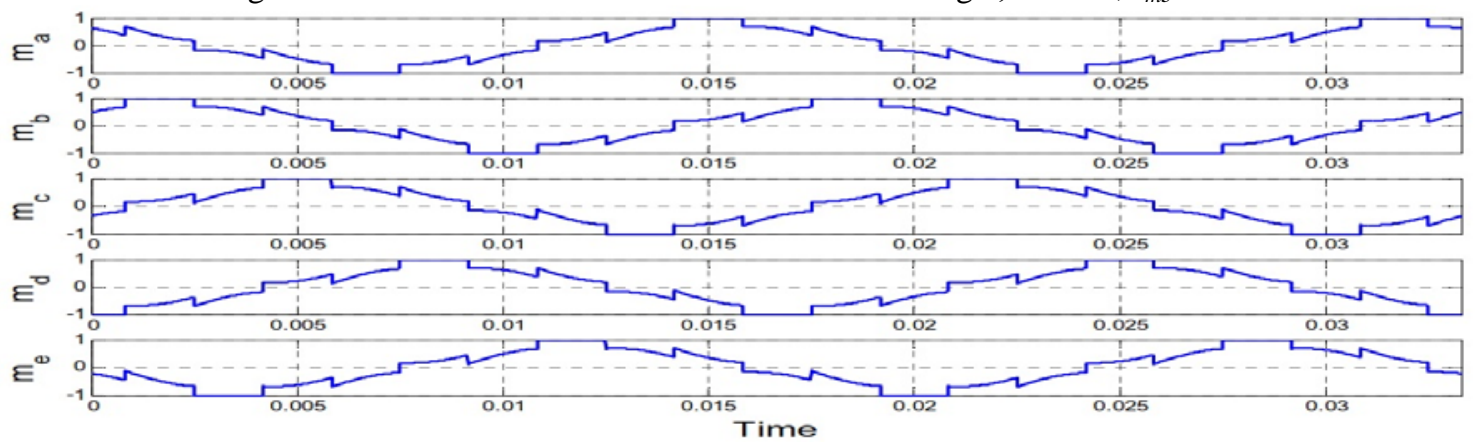

Figure 11. Five phase modulation signals for, $\delta=-36^{0}, V_{m 3}=+15 \mathrm{v}$

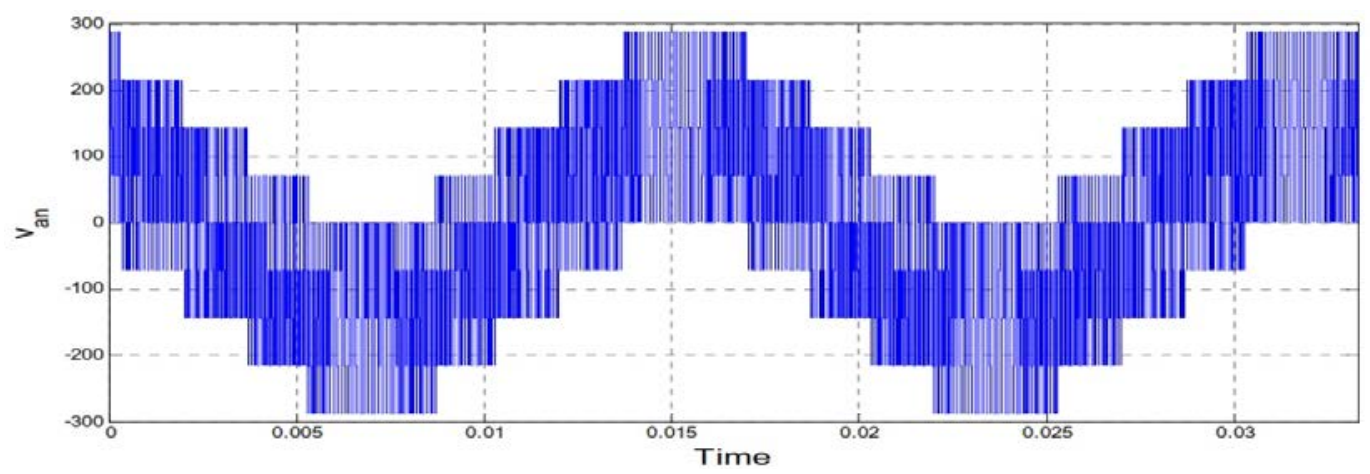

Figure 12. Phase 'a' load voltage $\delta=-36^{0}, V_{m 3}=+15 \mathrm{v}$

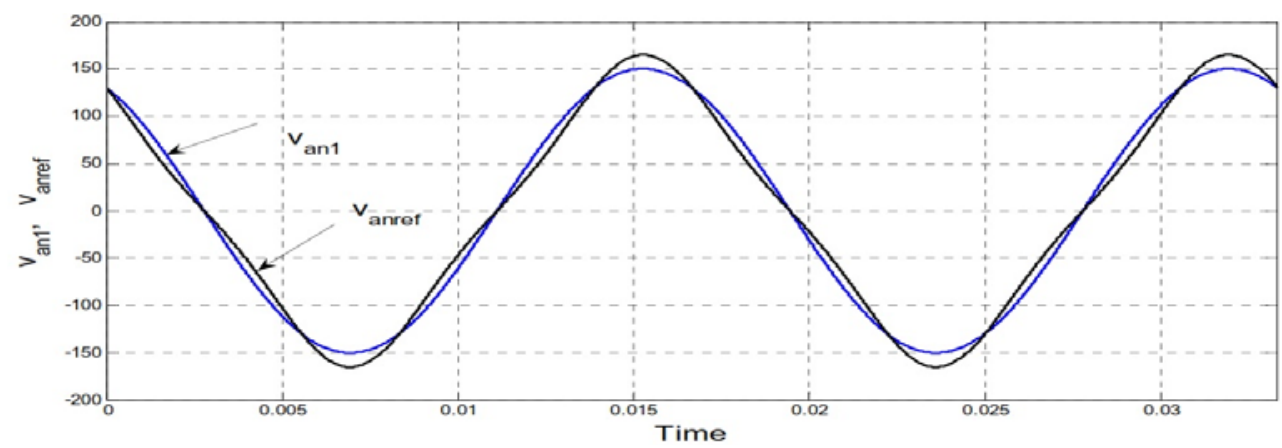

Figure 13. Phase 'a' fundamental and reference voltage, $\delta=0^{0}, V_{m 3}=+15 \mathrm{v}$

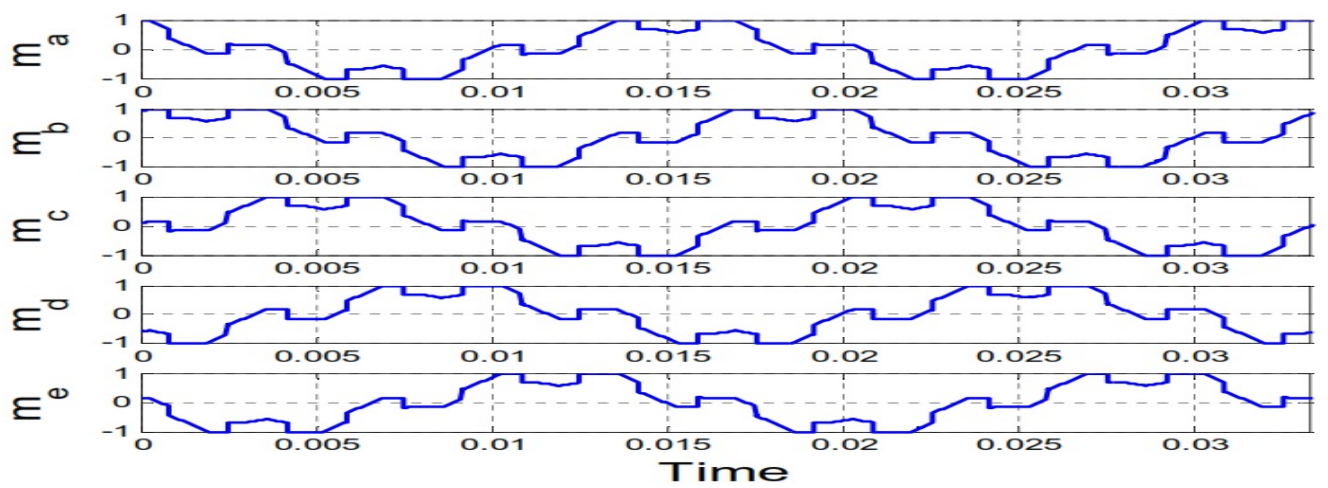




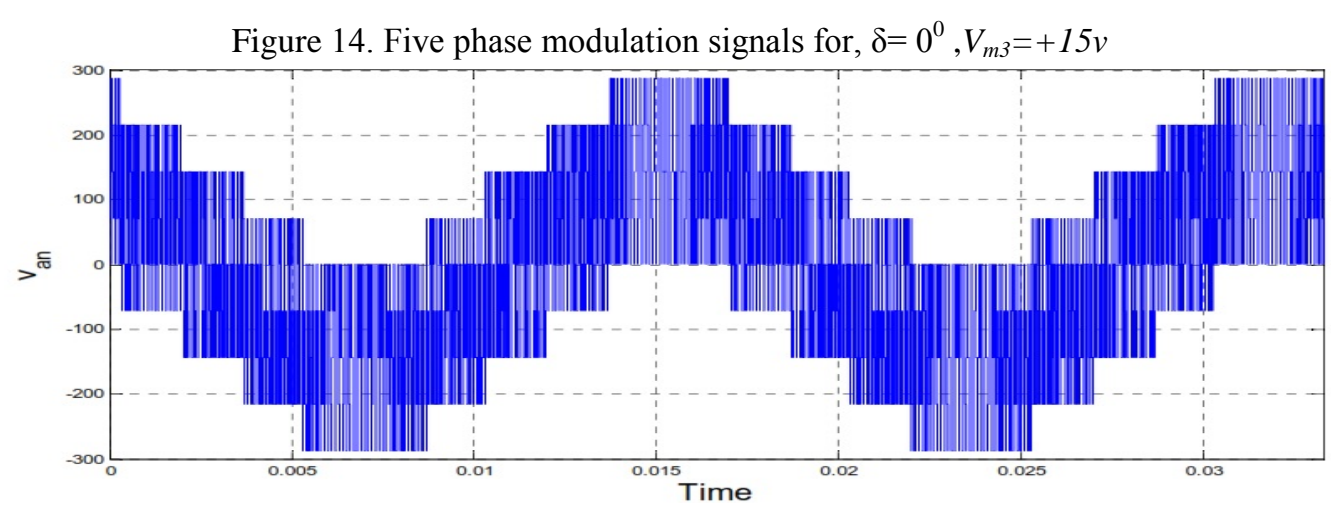

Figure 15. Phase 'a' load voltage $, \delta=0^{0}, v_{m 3}=+15 \mathrm{v}$

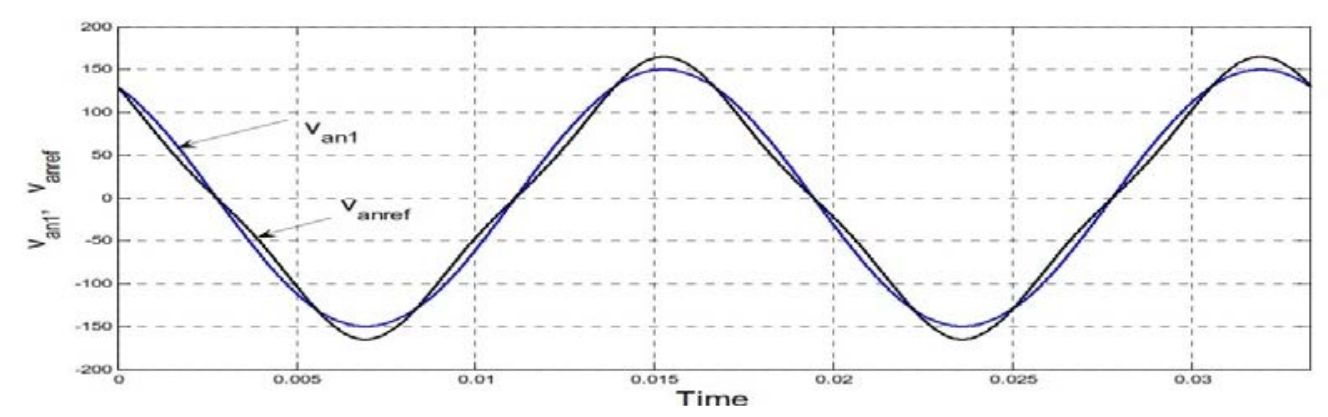

Figure 16. Phase 'a' fundamental and reference voltage, $\alpha=0.5, V_{m 3}=+15 \mathrm{v}$

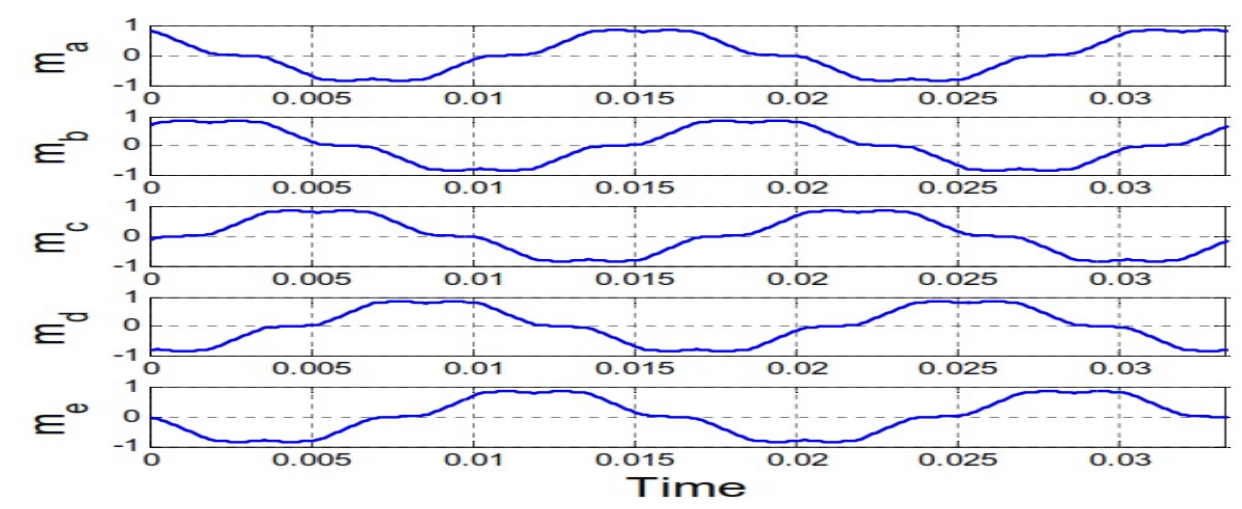

Figure 17. Five phase modulation signals for, $\alpha=0.5, V_{m 3}=+15 \mathrm{v}$

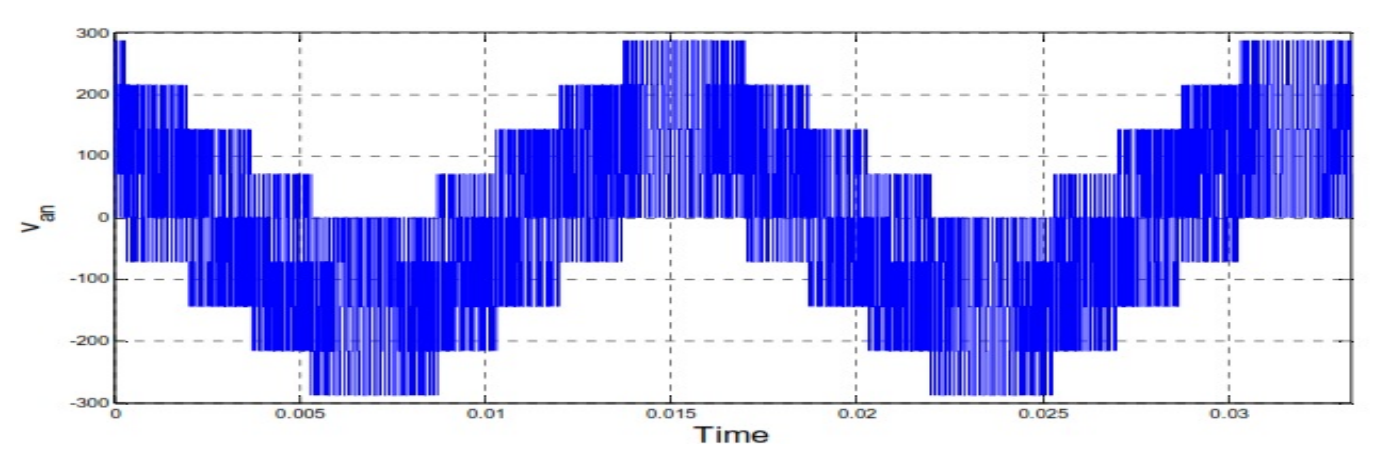

Figure 18. Phase 'a' load voltage $\alpha=0.5, v_{m 3}=+15 \mathrm{v}$ 


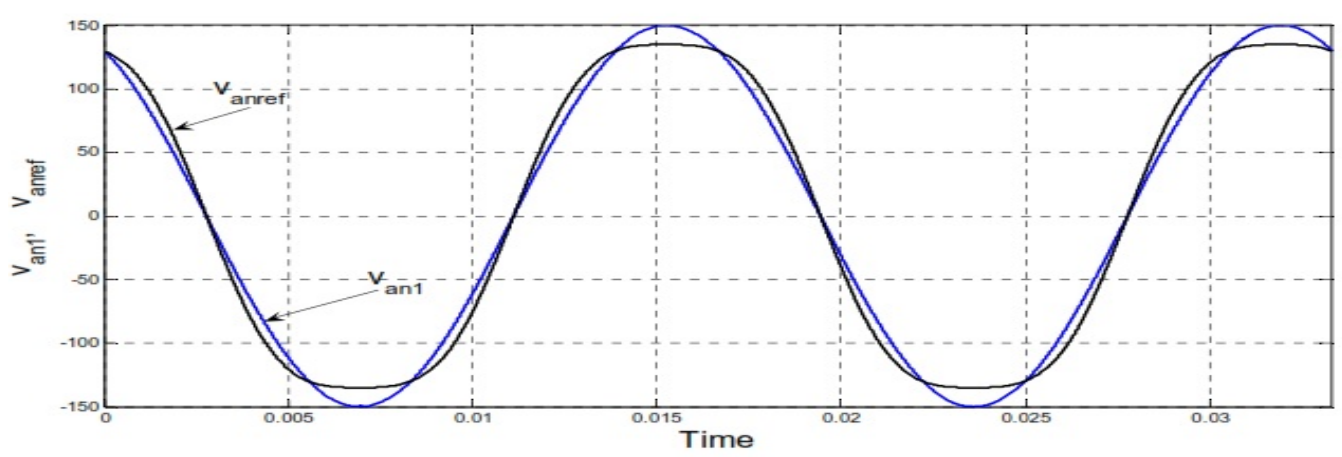

Figure 19. Phase 'a' fundamental and reference voltage, $\alpha=0.5, V_{m 3}=+15 \mathrm{v}$

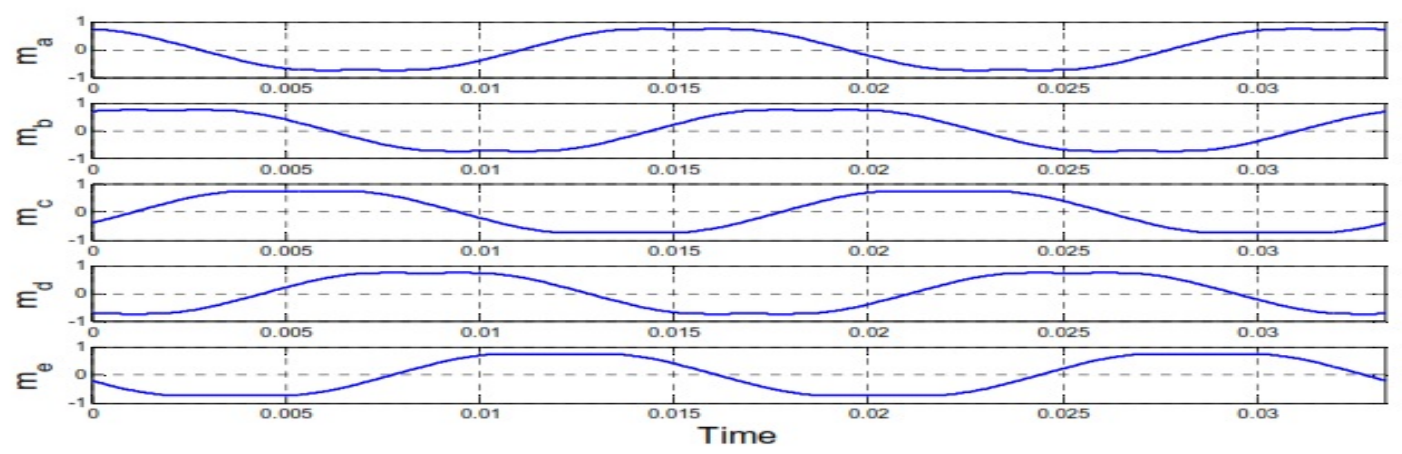

Figure 20. Five phase modulation signals for, $\alpha=0.5, V_{m 3}=-15 \mathrm{v}$

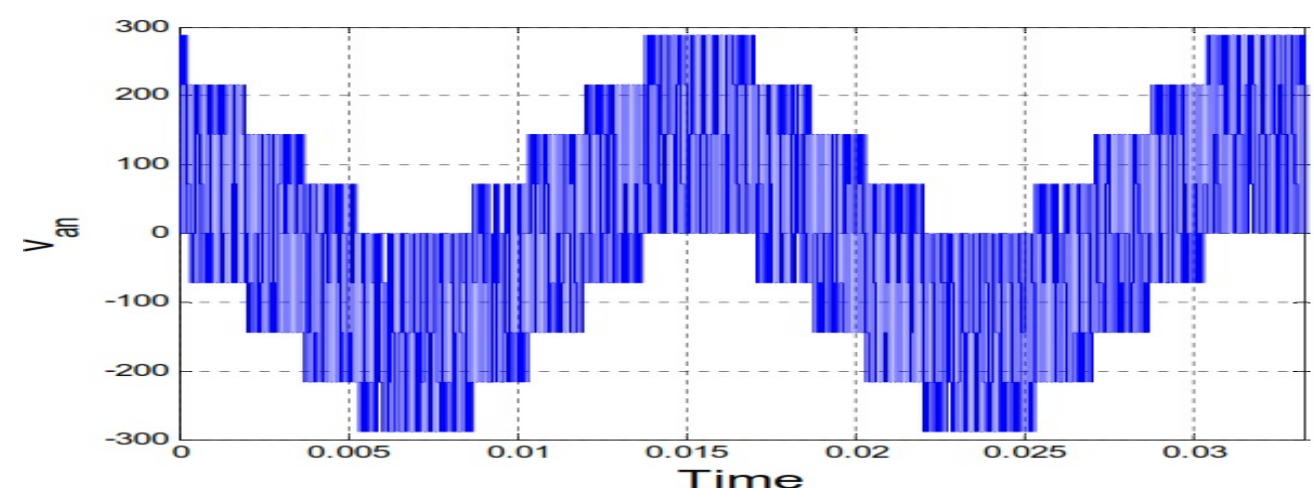

Figure 21. Phase 'a' load voltage $\alpha=0.5, V_{m 3}=-15 v$

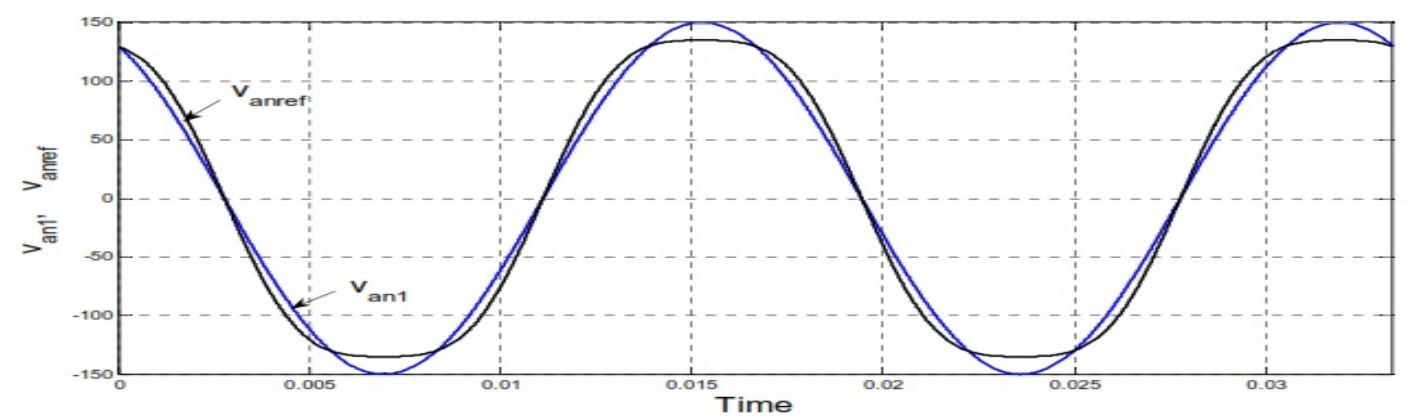

Figure 22. Phase 'a' fundamental and reference voltage, $\delta=0^{0}, V_{m 3}=+15 \mathrm{v}$ 


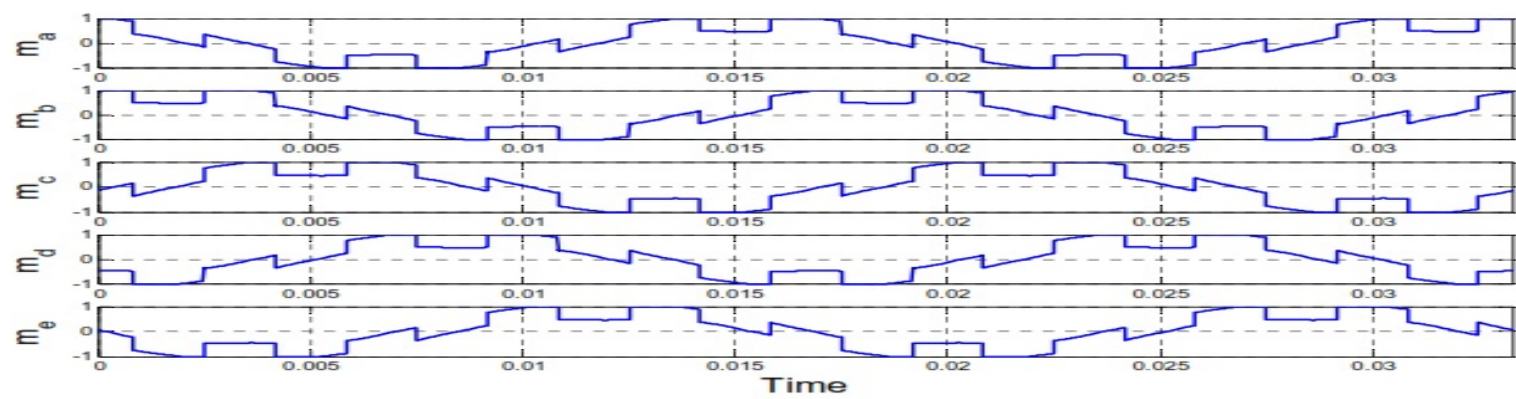

Figure 23. Five phase modulation signals for, $\delta=0^{0}, V_{m 3}=-15 \mathrm{v}$

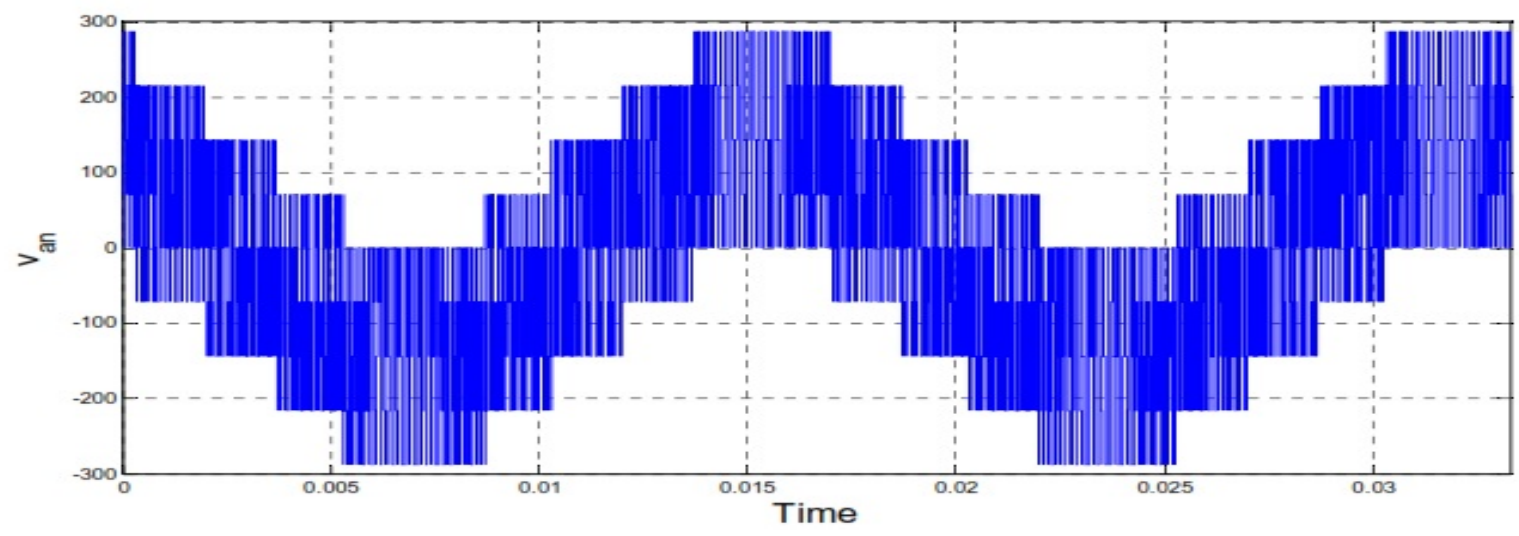

Figure 24. Phase 'a' load voltage $, \delta=0^{0}, V_{m 3}=-15 \mathrm{v}$

\section{SIMULATION RESULTS}

For, five phase induction machine is simulated by three sets of connections for below Figure 25(a), is assumed as star-connected the phase voltage across the machine windings are $v_{a s,}, v_{b s,}, v_{c s,}, v_{d s,}, v_{e s .}$. It is assumed to be conventionally delta connected the phase voltage across the machine windings are $v_{a s}-v_{b s}, v_{b s}$ $v_{c s}, v_{c s}-v_{d s}$ and $v_{d s}-v_{e s}, v_{e s}-v_{a s}$ from below Figure 25(b). In all simulation results,the no-load transients for the electromagnetic torque, $\mathrm{I}_{\mathrm{as}}, \mathrm{I}_{\mathrm{ar}}$ and rotor speed are presented. Then a rated amount of the torque of $8.5 \mathrm{~nm}$ is enforced at a time of instant 0.5 seconds and results also presented. The phase of the voltage as shown in below. In each different winding connection the machine is supplied from the mains (online) through fedinverter and derived voltage and current relationships of three different stator windings are given below [3][7].

Conventional Star Connection:

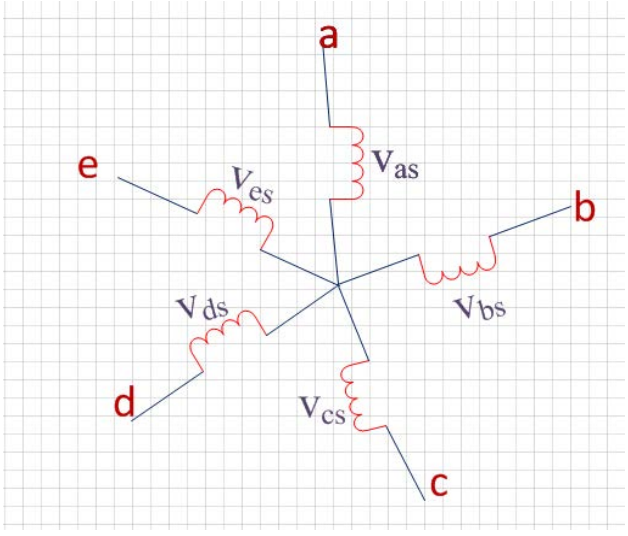

Figure 25(a) 
The phase voltage is given by

Vas $=v m \cos (\theta e)$

$V b s=v m \cos (\theta e-2 \pi / 5)$

$V C S=v m \cos (\theta e-4 \pi / 5)$

$V d s=v m \cos (\theta e-6 \pi / 5)$

Ves $=v m \cos (\theta e-8 \pi / 5)$

line-line voltage is given by

$V a b=1.1756 v m \cos (\theta e+3 \pi / 10)$

$V b c=1.1756 v m \cos (\theta e-\pi / 10)$

$V c d=1.1756 v m \cos (\theta e-5 \pi / 10)$

$V d e=1.1756 v m \cos (\theta e-9 \pi / 10)$

Vea $=1.1756 v m \cos (\theta e+7 \pi / 10)$

line and phase currents are same

$i a=\operatorname{Im} \cos (\theta e+\delta)$

$i b=\operatorname{Im} \cos (\theta e+\delta-2 \pi / 5)$

$i c=\operatorname{Im} \cos (\theta e+\delta-4 \pi / 5)$

$i d=\operatorname{Im} \cos (\theta e+\delta-6 \pi / 5)$,

$i e=\operatorname{Im} \cos (\theta e+\delta-8 \pi / 5)$

Conventional Delta Connection:

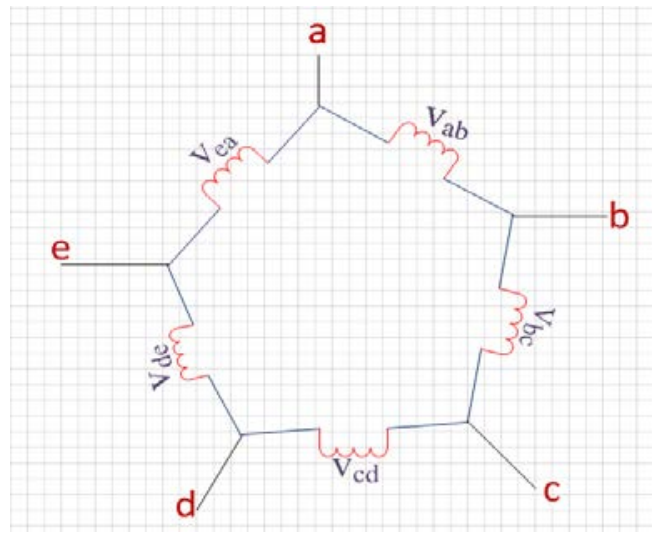

Figure 25(b)

phase and line-to-line voltages are same are given by

$V a b=V a s=1.1756 v m \cos (\theta e+3 \pi / 10)$

$V b c=V b s=1.1756 v m \cos (\theta e-\pi / 10)$

$V c d=V c S=1.1756 v m \cos (\theta e-5 \pi / 10)$

$V d e=V d s=1.1756 v m \cos (\theta e-9 \pi / 10)$,

$V c d=V c s=1.1756 v m \cos (\theta e+7 \pi / 10)$.

phase currents are given by

$i a b=1.1756 \operatorname{Im} \cos (\theta e+\delta+3 \pi / 10)$

$i b c=1.1756 \operatorname{Im} \cos (\theta e+\delta-\pi / 10)$

icd $=1.1756 \operatorname{Im} \cos (\theta e+\delta-5 \pi / 10)$

ide $=1.1756 \operatorname{Im} \cos (\theta e+\delta-9 \pi / 10)$

iea $=1.1756 \operatorname{Im} \cos (\theta e+\delta+7 \pi / 10)$.

line currents are given by

$i a=1.3820 \operatorname{Im} \cos (\theta e+\delta)$

$i b=1.3820 \operatorname{Im} \cos (\theta e+\delta-4 \pi / 10)$

ic $=1.3820 \operatorname{Im} \cos (\theta e+\delta-8 \pi / 10)$

$i d=1.3820 \operatorname{Im} \cos (\theta e+\delta+8 \pi / 10)$

$i e=1.3820 \operatorname{Im} \cos (\theta e+\delta+4 \pi / 10)$ 


\subsection{Without Third Harmonic Voltage Injection}

The fundamental frequency of inverter fed induction motor with a basic voltage is $60 \mathrm{HZ}$. Figure 26 through 33 shows different results from machine windings. Whereas, Figure 26 through Figure 29 shows normal operation without using inverter, whereas, Figure 30 through Figure 33 results when a five phase machine is supplied through inverter. Figure 26, 27, 30 and 31 the machine connection is star connection. Figure 28, 29, 32 and 33 the stator winding is delta connection (conventionally).The maximum value of the elemental voltage maintained is $187.79 \mathrm{~V}$ and D.C voltage is $360 \mathrm{~V}$.In all the results $\mathrm{I}_{\mathrm{as}}, \mathrm{V}_{\mathrm{as}}, \mathrm{T}_{\mathrm{e}}, \mathrm{I}_{\mathrm{ar}}$ and speed are shown as follows.

\section{SIMULATION RESULTS OF INDUCTION MOTOR WITHOUT USING INVERTER}
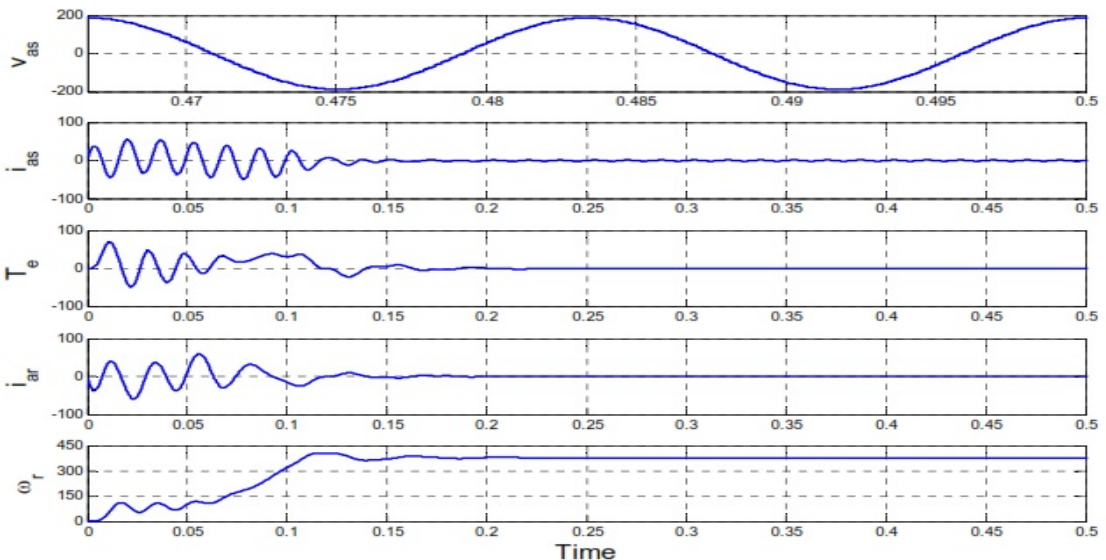

Figure 26. Stator Starting Transients - For Star Connection

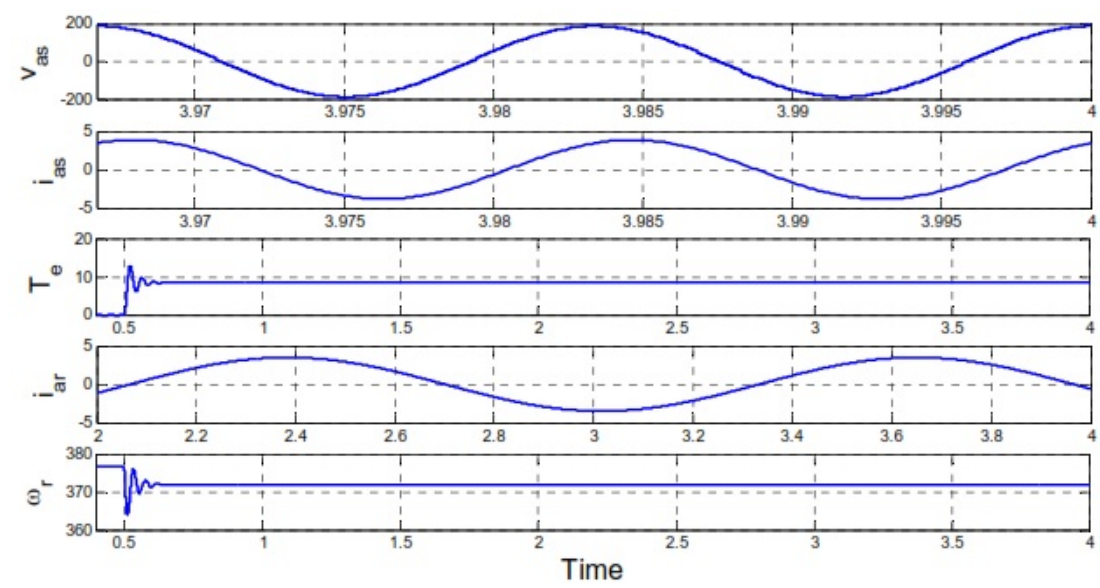

(a)

(b)

Figure 27. Load Transients on Stator side - Star Connection 

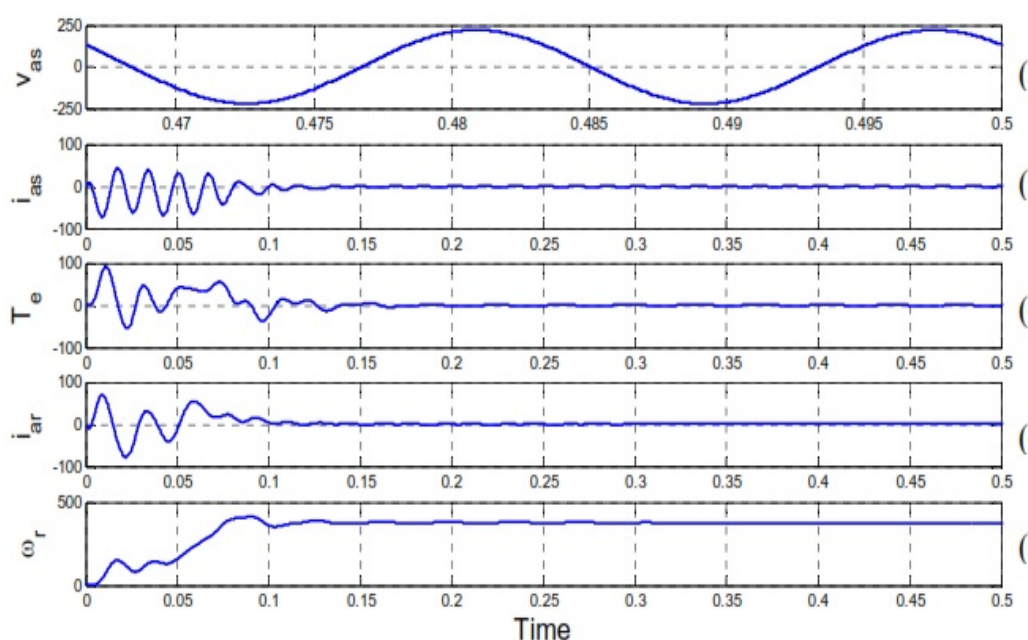

Figure 28. Stator Starting transients - Delta Connection
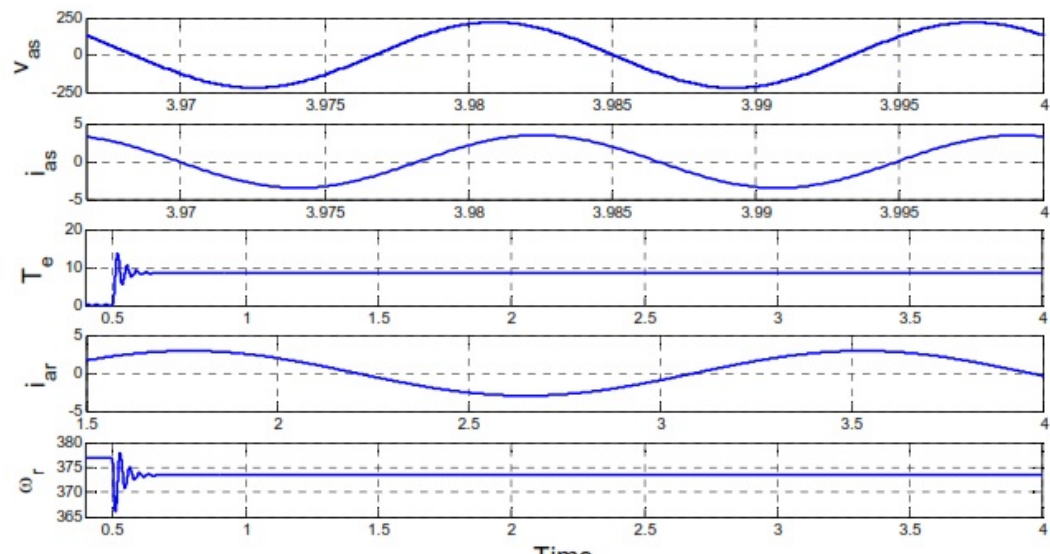

Figure 29. Load transients on stator side - Delta Connection

SIMULATION RESULTS OF INDUCTION MOTOR USING INVERTER
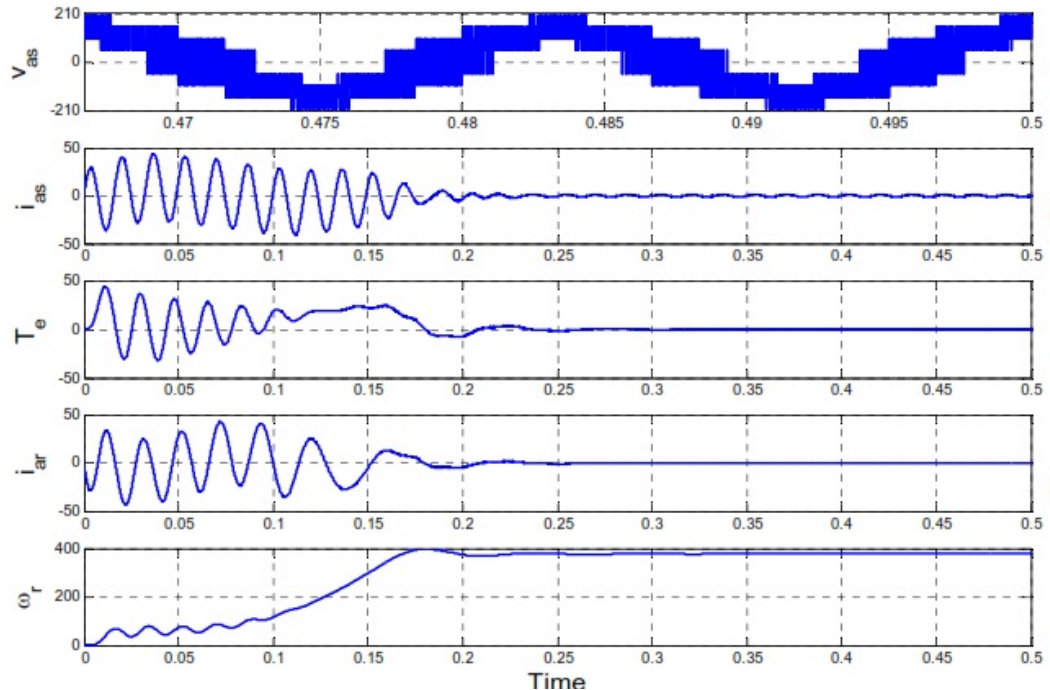

Figure 30. Stator Starting transients - Star Connection 


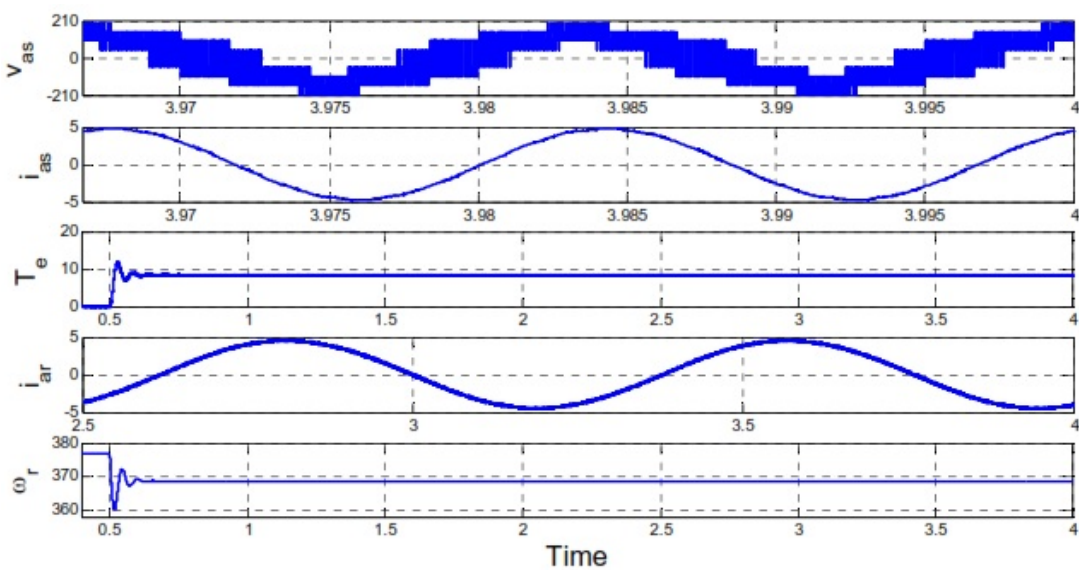

Figure 31. Load transients on stator side - Star Connection
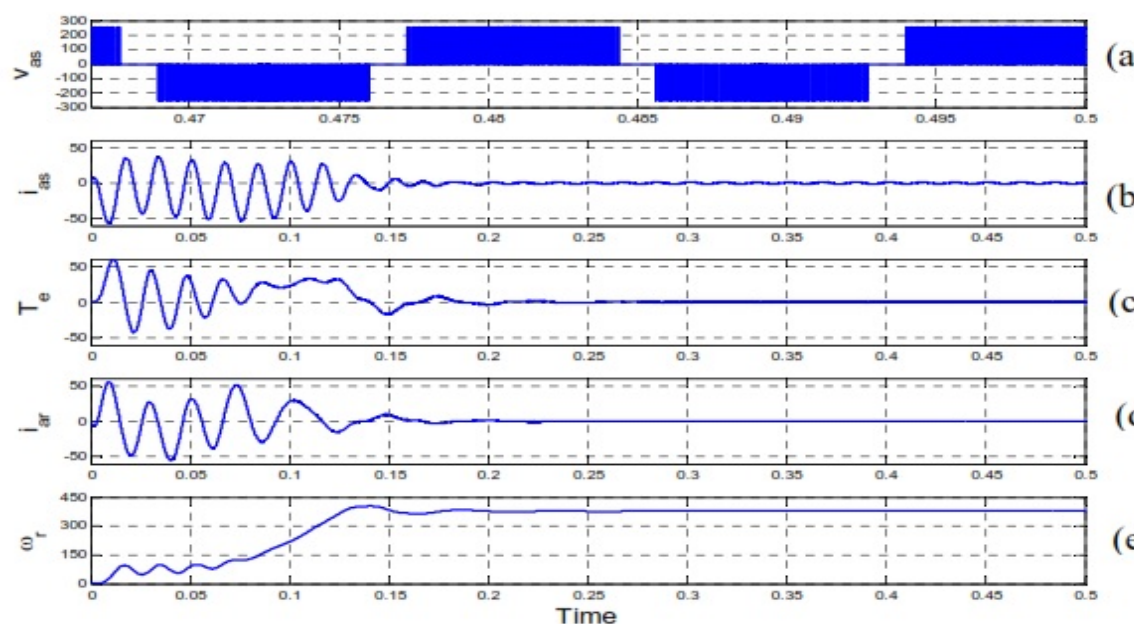

Figure 32. Stator Starting transients - Delta Connection
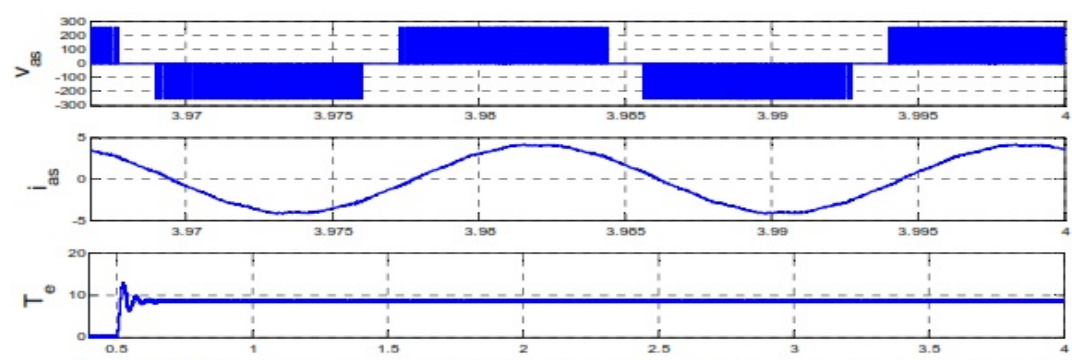

(c)
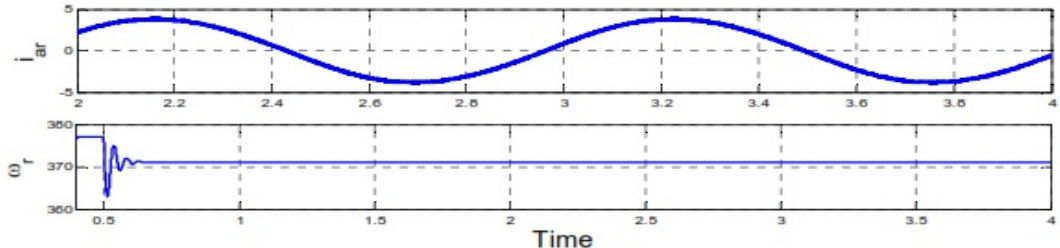

Figure 33. Load transients on stator side - Delta Connection 


\subsection{Injection of Third Harmonic Supply Voltage Component}

The third harmonic voltage with the $10 \%$ magnitude of the fundamental was added to the fundamental voltage. The simulation analyzes the effect of this amount if at all there is any significant in the overall torque caused by third harmonic component. Figure 34 through 37 show normal operation without an inverter, whereas Figure 38 through Figure 41 results when a five phase machine is supplied through inverter. Figure 34, 35, 38, 39, shows the machine winding is star connected; While Figure 36, 37, 40, 41, shows in delta form. (conventionally). In all the simulation results the torque can be represented as fundamental, third, total torque. Peak amount of the fundamental voltage used in this simulation is $187.79 \mathrm{~V}$ and that of the third harmonic component is $18.779 \mathrm{~V}$. The dc voltage is $360 \mathrm{~V}$.

\section{SIMULATION RESULTS OF INDUCTION MOTOR WITHOUT USING INVERTER}

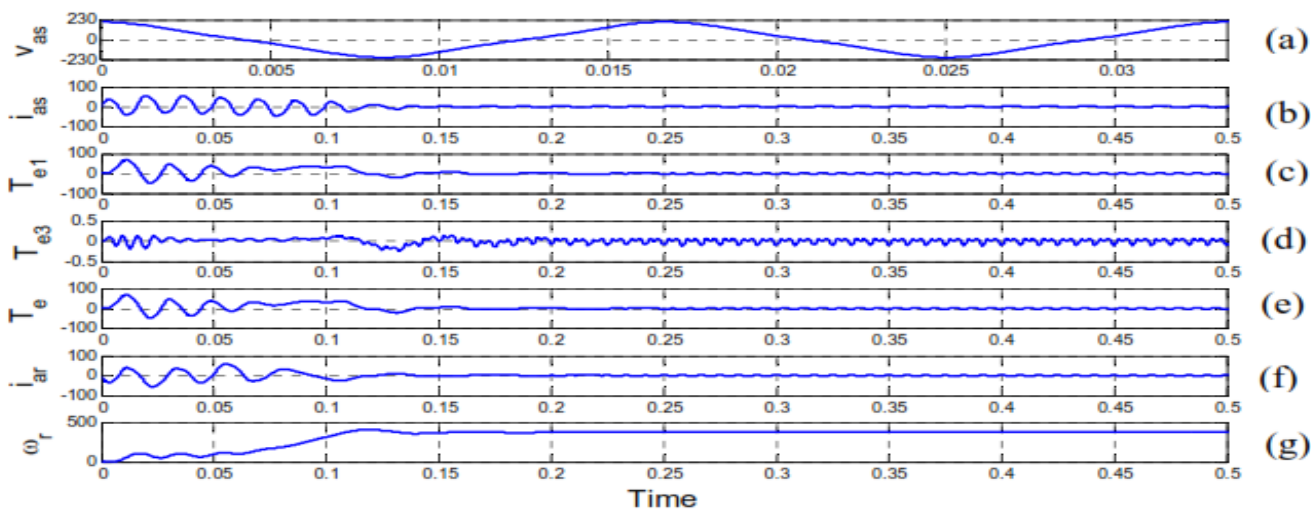

Figure 34. Stator Starting transients - Star Connection

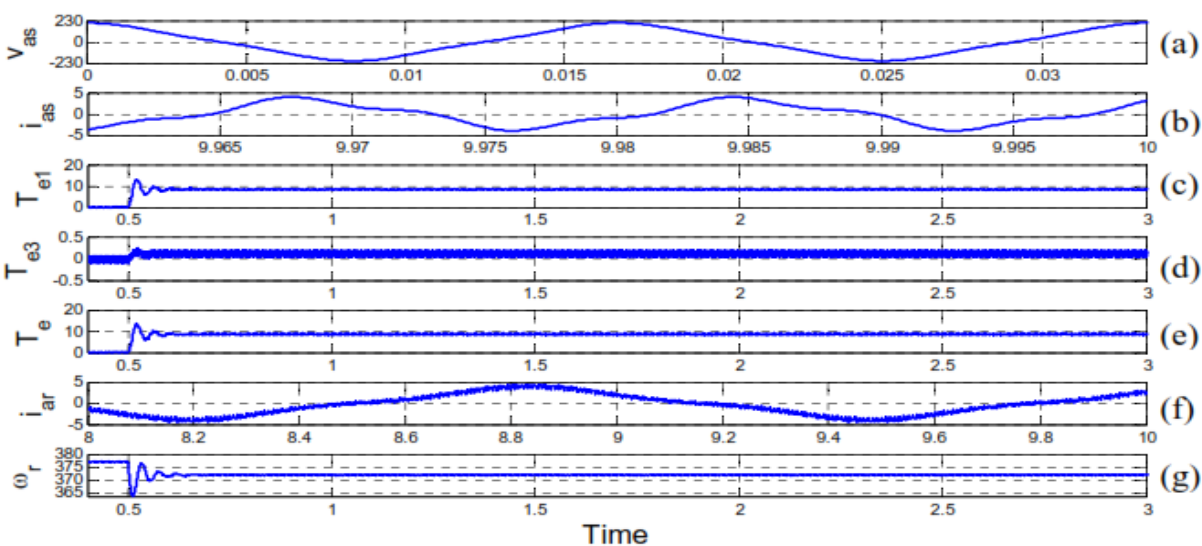

Figure 35. Load transients on stator side - Star Connection 


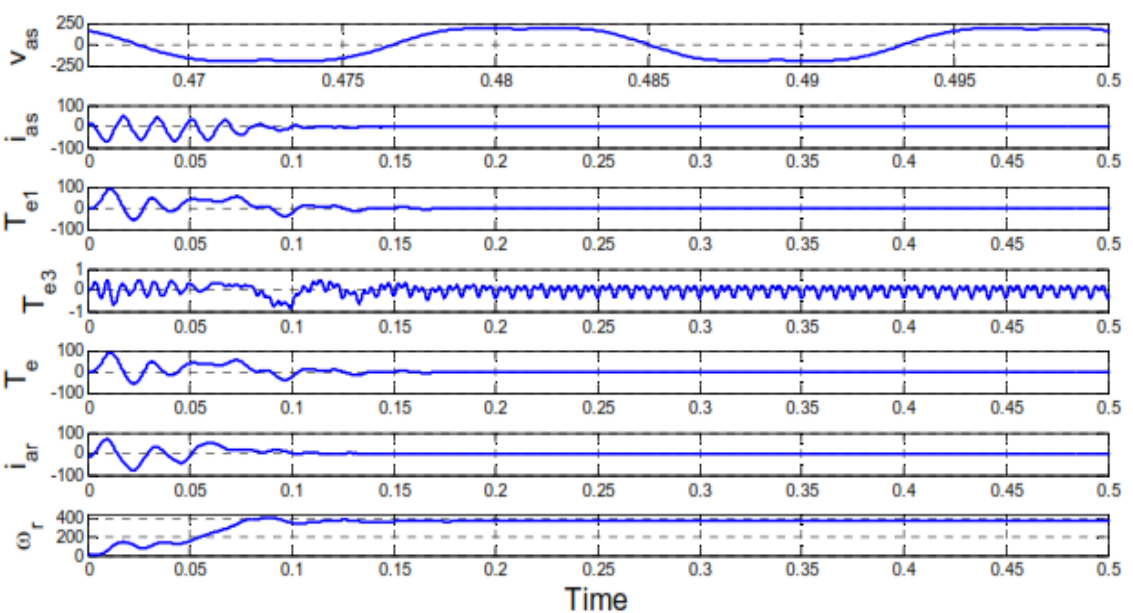

Figure 36. Stator Starting transients - Delta Connection

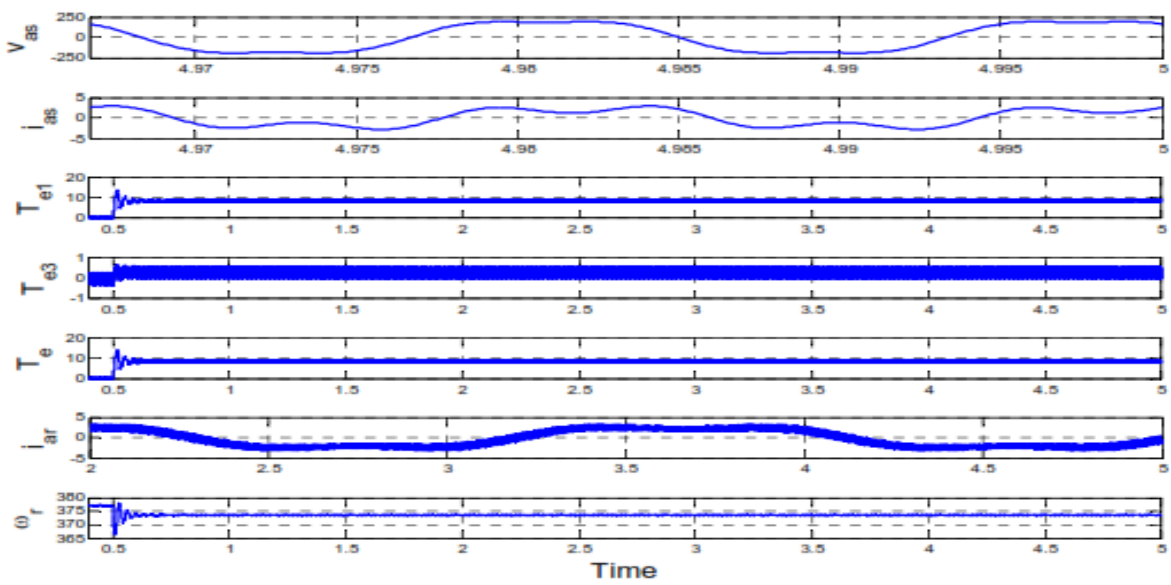

Figure 37. Load transients on stator side - Delta Connection

SIMULATION RESULTS OF INDUCTION MOTOR USING INVERTER

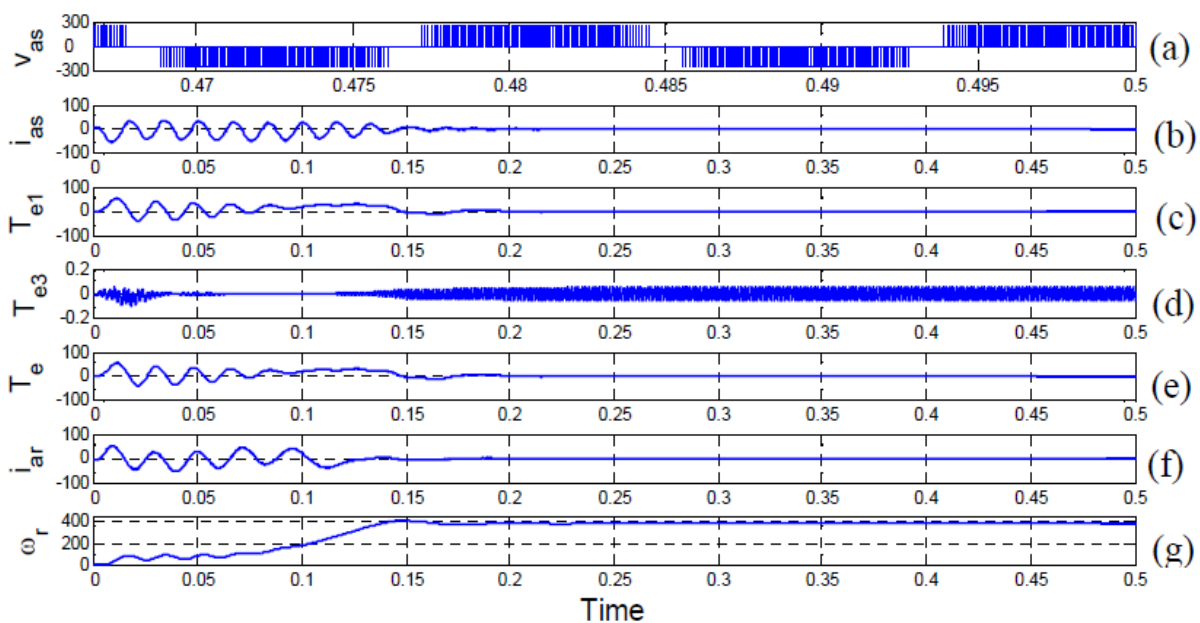

Figure 38. Stator Starting transients - Star Connection 


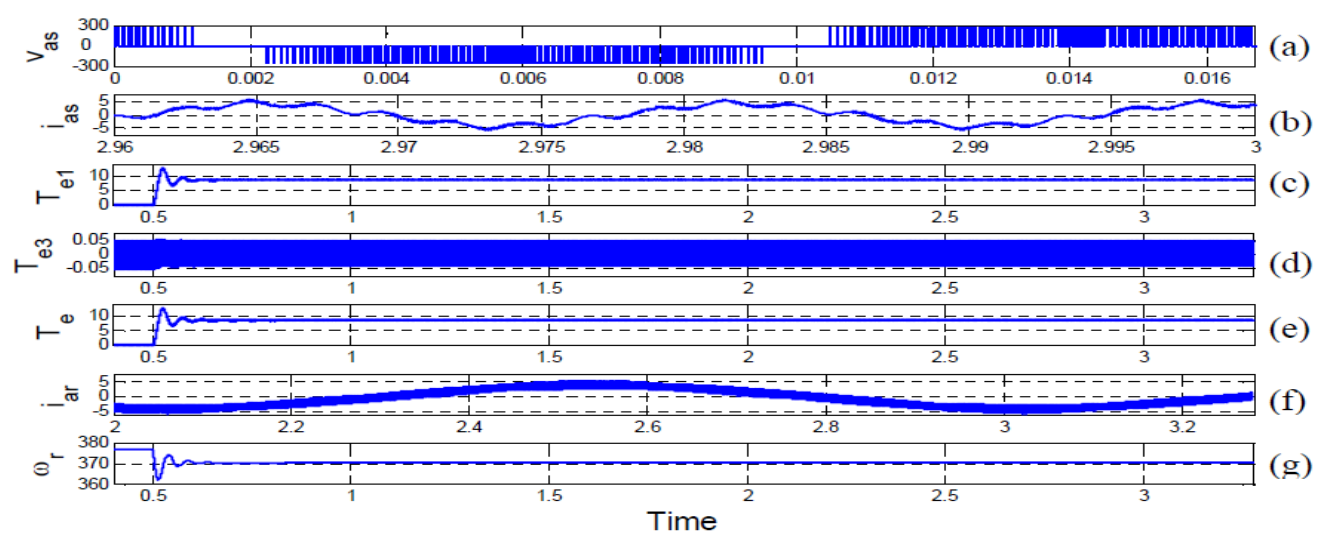

Figure 39. Load transients on stator side - Star Connection

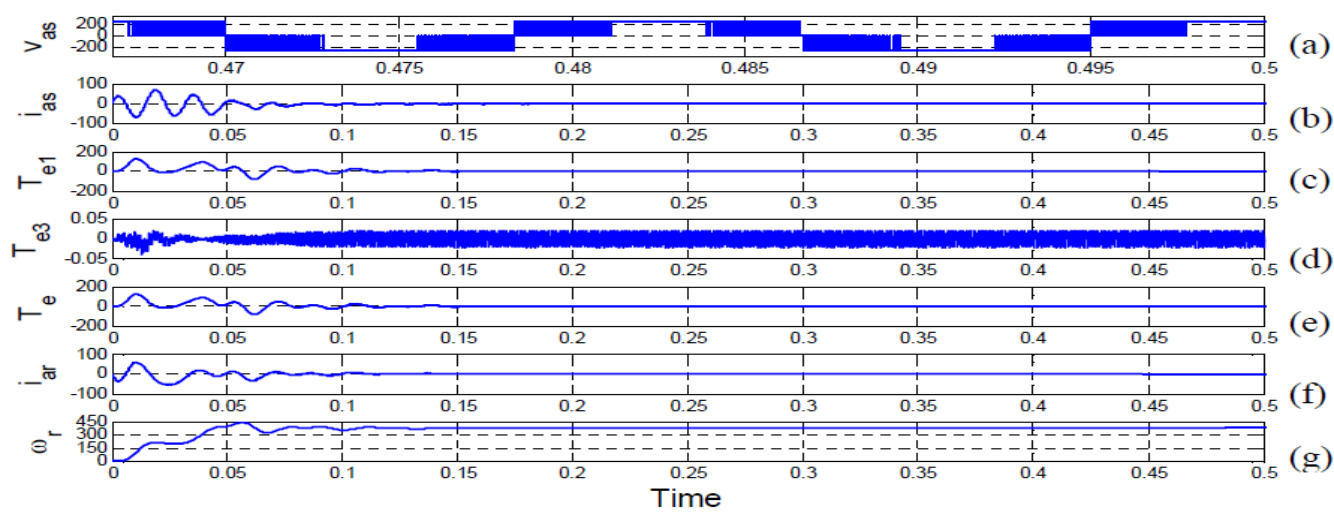

Figure 40. Stator Starting transients - Delta Connection

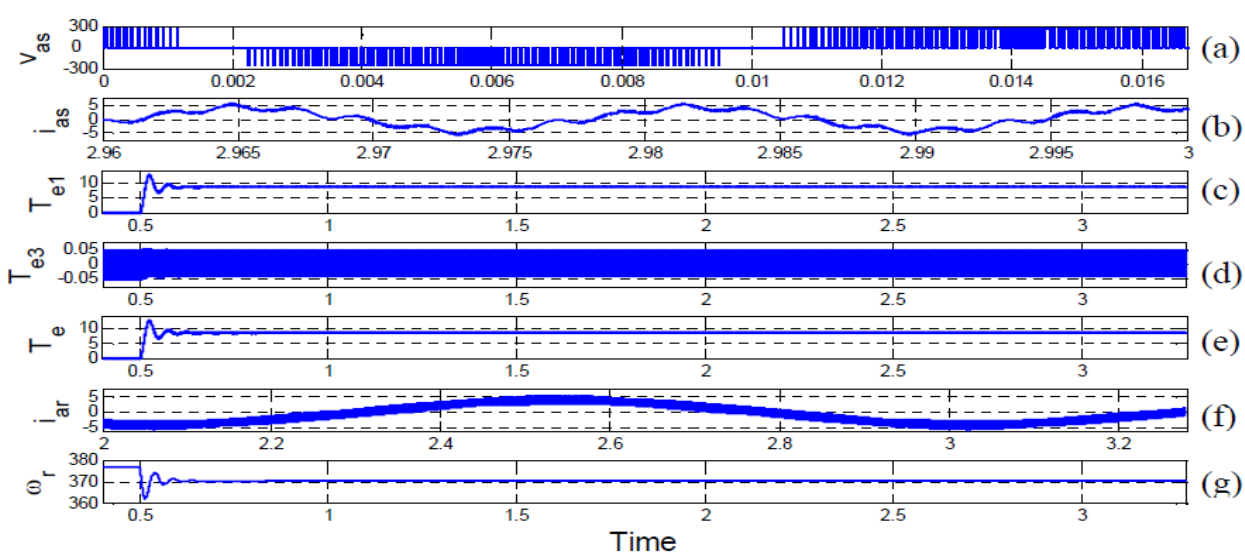

Figure 41. Load transients on stator side - Delta Connection

\section{CONCLUSION}

The five-phase carrier based pulse width modulation inverter schematic has to be analysed. It is used in supplying the Inverter fed five phase induction machine. Both, the basic and harmonic components have considered. Hence, harmonic voltage of the $10 \%$ magnitude of the elemental voltage has been injected. Hence, the outcome of this injected voltage as shown in the results. The third harmonic torque component has a finite value, although not to contributing the much to require the total torque. Also, three different stator windings has to be considered that is star based connection and conventional delta based connection. For, the 
delta connections two peak values of the peak phase voltage have been considered. The ratio of the phase voltage magnitude delta mode to star mode is 1.1756. This means more voltage can be obtained in the machine windings without a need of increasing the supply voltage.

\section{ACKNOWLEDGMENT}

The Science and Engineering Research Board department sanctioned a grant for this project. I am very thankful to this department and my supervisor Dr.M.Venugopala Rao.

\section{REFERENCES}

[1] S. Karugaba and J. Ojo, "A Carrier Based PWM Modulat ion Technique f or Balanced and Unbalanced Ref erence Volt ages in Mult iphase Volt age Source Invert ers,” IEEE Transact ions on Indust ry Applicat ions, 2012.

[2] Karugaba, et al., "A method $\mathrm{f}$ or $\mathrm{f}$ ive-phase carrier based PWM modulat ion $\mathrm{f}$ or balanced and unbalanced ref erence volt ages,” 2010 IEEE Energy Conversion Congress and Exposit ion, 2010.

[3] K. N. Pavithran, et al., "Studies on inverter-fed Five-Phase Induction Motor Drive," IEEE Transactions on Power Electronics, vol/issue: 3(2), pp. 1177-1184, 1988.

[4] O. Ojo, "The generalized Discontinuous PWM Scheme for Three-Phase Voltage source Inverters," IEEE Transactions on Industrial Electronics, vol/issue: 51(6), pp. 1280-1289, 2004.

[5] L. Pereira, et al., "Model of a fivephase induction machine allowing for harmonics in the air-gap field, Part II: Transformation of coordinates and d-q models," in Proc. IEEE IECON, Busan, Korea, pp. 1682-1687, 2004.

[6] L. Pereira, et al., "General model of a five-phase induction machine allowing for harmonics in the air-gap field," IEEE Transactions on Energy Conversion, vol/issue: 21(4), pp. 891-899, 2006.

[7] D. Casadei, et al., "Space vector modulation based on a multidimensional approach for multiphase inverters with an odd number of phases," in Proc. IEEE Power Electron. Spec.Conf., pp. 1351-1357, 2008. 